\title{
Reflections on How Ancient Egyptian Comparative History is Done: from Microhistory to Cliodynamics
}

\author{
John Baines \\ University of Oxford \\ john.baines@orinst.ox.ac.uk
}

This comparative volume of the Journal of Egyptian History is in the excellent spirit of an aside in a 2016 article of Norman Yoffee on studying ancient Egypt's parallel civilization: "... I am of the school that believes that no one knows Mesopotamia who knows Mesopotamia only." Contributors to this volume may substitute Egypt, China, Tenochtitlán or-for several of them-a whole range of polities or societies, for the Mesopotamia of Yoffee's aphorism; but all of them will agree with its spirit. I would add that those who think they know only Egypt - the perhaps endangered species of Egyptological isolationistsmisled and mislead themselves because they also know another place: wittingly or unwittingly, they inform their approach to ancient Egypt with the Social Construction of Reality ${ }^{2}$ of the society in which they live. In most cases, that reality is a large occidental state of the nineteenth to twenty-first centuries. Twenty-first century states, in particular, offer a point of departure for thinking about ancient Egypt only insofar as the two state societies may be nearly as different from each other as can now be conceived. Something can be gained by comparing phenomena that are very unlike one another, but comparing societies that share more than just being "states" is far more likely to be illuminating than having the modern world as the main point of reference. (This is not to speak of the non-state societies of prehistory, which are on the fringe of this journal's coverage.)

Thus, the contributors to this volume are comparatists. What does that mean? Societies can be compared in many ways. Not all the articles here focus on situating their comparisons in relation to specific theoretical agendas. It may nonetheless be useful to provide some reflections on what is involved,

1 Yoffee, "The Evolution of Fragility," 9.

2 The title of a famous book by Berger and Luckmann (1966). 
as well as what potential and what limitations are offered by a variety of approaches, including a couple that happen not to be represented here.

First, I note one approach that is traditional in Egyptology and general ancient history but is not evident in this volume. The volume's authors include more than one who has published a synthesizing history of Egypt, but here they do not address how comparison may contribute toward producing improved historical narratives, either for ancient Egypt or for anywhere else. This reticence is understandable in a field that is archaeologically recovered: the absence of a continuing tradition from antiquity to modern interpreters seems to stand in the way of easy constructions of narrative history. That is perhaps the most difficult style of historical research to conduct on many ancient societies, and I am full of admiration for colleagues who write such narratives. Archaeology, however, is better at modes of research and synthesis that are different from narrative; this is particularly true of prehistory, but the point also applies to historical periods. In terms of historical method, comparative approaches to narrating the history of ancient civilizations and integrating it with archaeology could be very valuable. Pairs of traditions that have often been treated in isolation might inform such an undertaking. China and Japan offer possibilities as strong, relatively distinct historical traditions that came late to archaeology and have been imbued with a more understandable nationalism than the vicarious nationalism of much non-Egypt-based Egyptology.

Second, it is worth considering styles and purposes of global history for a moment before presenting and commenting on some methods. It is early days, but so far the third millennium CE has seen a great increase in interest in global history. As Gianluca Miniaci notes in his concluding essay, an important gain of global history is that it decenters the focus and makes the subject as a whole more diverse. Historians can also base their discourse and arguments more on non-textual evidence than has generally been the case. A decentered, more material history is less at risk of teleological reasoning than traditional ancient history (I return to this point below). Across the whole world, both history and archaeology have all too often been conscripted for triumphalist, present-oriented narratives of a forward "progress" that has proved to be illusory. If a viable and responsible history is to be practiced, it is essential to avoid such pitfalls, and global history has a much better chance of doing so than many traditional modes. Sole-authored global interpretive histories of the style of Arnold Toynbee's multi-volume A Study of History (1934-1961), ${ }^{3}$ most of which had undertones or explicit purposes of teleology, are among the least

3 As for several other topics I mention below, Wikipedia offers a convenient brief summary: https://en.wikipedia.org/wiki/A_Study_of_History (consulted 15 December 2020). 
read books of today. The collaborative histories that are beginning to appear offer a more realistic way of mastering the evidence, as well as the prospect of a greater diversity of viewpoints and methods. Their methods include those of archaeology, which are prominent in the Cambridge World History volumes that I mention below.

Global history also offers a slightly improved possibility of addressing ancient societies "as they actually were" (in a different sense from that of Leopold von Ranke ${ }^{4}$ ) than a history that sees ancient Egypt essentially as a prelude to the classical Mediterranean world. A premise that I share with the authors in this volume is that Egypt has much to contribute to global history and that its contributions have hitherto been fewer, and have had less impact, than is to be desired.

In another perspective, academic history in general shares with Egyptology the characteristic of not being a unified discipline, while the two differ in their styles of disunity. History applies a vast range of methods and/or disciplines to studying phenomena of the past, either in order to describe and "understand" it, or to "explain" it (for more on these two aims, see below). Egyptology, which one could term a branch of Area Studies if that designation were more widely current, uses disciplines, from natural science to linguistics, to gain access to ancient phenomena, but without a single umbrella context apart from its geographical location as a part of Northeast Africa.

Both history and Egyptology often produce rich, small-scale studies, such as those made famous by the Annales school, exemplified by Emmanuel Le Roy Ladurie's Montaillou, village occitan de 1294 à 1324 (1978 [1975]), ${ }^{5}$ or Italian microhistory, notably in Carlo Ginzburg's The Cheese and the Worms: the Cosmos of a Sixteenth-century Miller (1980 [1976]). In Egyptology one could cite as parallels various works on Deir el-Medina, or for the Roman Period P.J. Parsons's The City of the Sharp-nosed Fish: Greek Lives in Roman Egypt (2007). In such cases the close analysis of exceptional, primarily documentary, sources is very effective, and pairs of these books can be profitably compared. But despite the great value of these works, it is difficult to generalize methods or results from comparing them. Rather, the reader gains from them imaginative stimuli for thinking about "what life was like," its diversity, and meanings that it held for actors outside the realm of rulers and elites. But this should not delude us into

4 “... wie es eigentlich gewesen", which Wikipedia renders "the way it happened." From Wikipedia one also learns that Ranke attended the same school as the founder of German Egyptology, Richard Lepsius, Schulpforta near Naumburg (but Ranke was older): https:// en.wikipedia.org/wiki/Leopold_von_Ranke (consulted 17 December 2020).

5 The 1978 English translation has the different title Montaillou: Cathars and Catholics in a French Village, 1294-1324. 
believing that we are "thinking like" ancient people in more than cautiously qualified ways. Even the vast record from Deir el-Medina is far more fragmentary and difficult to order than the Inquisition report underlying Montaillou, while that book may suggest ways of thinking about the Egyptian village that might not otherwise occur to an Egyptologist. The material remains of Deir el-Medina and its artifactual record, by contrast, could inform interpretations of the essentially verbal evidence for Montaillou.

Often scholars add another ingredient to their mix of methods: societies are compared while adopting an approach informed by specific disciplines, in particular those of the social sciences. Much foundational sociology used historical materials as its evidence base, or indeed has been termed historical sociology, so that there is often no clear dividing line between sociology as a "discipline" and history as a methodological congeries. This crossover between history and sociology continues. Another common and important tactic is to study societies comparatively through the lens of a particular phenomenon. Urbanism is a case in point, conveniently exemplified in two independently produced works, Norman Yoffee's edited volume, Early Cities in Comparative Perspective, 4000 BCE-1200 CE (2015), and Michael E. Smith's "Ancient Egyptian Urbanism in a Comparative, Global Context" in the current volume.

Yoffee's volume is the third of seven (nine physical books) in the Cambridge World History and thus is closely relevant to the present journal volume. Yoffee's sections address ways of looking at cities comparatively through themes, under which are grouped chapters about specific societies. These chapters are followed by short synthesizing chapters in which the same authors bring those materials together and draw out commonalities and contrasts. The themes are: arenas of performance; information technologies; landscapes; distribution of power; early cities as creations; early imperial cities. The whole is enveloped by an introduction and conclusion that look to the past of research on ancient cities and to the potential of cities, not just ancient ones, for further interpretation and for an uncertain future. The next volume, Craig Benjamin, ed., $A$ World with States, Empires, and Networks, 1200 BCE-90o CE (2015), has a thematic opening part, "Global Histories," with chapters on topics such as gender and slavery, as well as an inspiring treatment of "Art" by Robert Bagley. ${ }^{6}$

While all this comparison is creatively organized and takes definitions of cities and states into account, it does not generate testable hypotheses; its aims are different. By contrast, Smith is soon to publish a book that will incorporate a partly trait-list-based classification of urbanism; from his description it appears that in some ways this will offer an evolutionary model through its

6 In A World with States, Empires, and Networks, 179-234. 
focus on commercialization. ${ }^{7}$ One conclusion that he draws is that, according to his criteria, ancient Egypt before the New Kingdom was only weakly commercialized and its urbanism was tempered by its command economy. That economy, however, was far more durable than his comparanda of the Inka empire and the small-scale palace economies of the Bronze Age Aegean. This striking difference between cases is suggestive of a need for further refinement of interpretations, perhaps of all three examples.

Not by chance, Smith is (if I am not mistaken) the only contributor to this volume who cites a 2018 article of Daniel Hoyer and J.G. Manning, "Empirical Regularities across Time, Space, and Culture: a Critical Review of Comparative Methods in Ancient Historical Research." Their treatment, which includes valuable sketches of issues relating to the history of Ptolemaic and Roman Egypt, is exceptional in its clear discussion of methods and issues in comparison and in broader historical research, particularly where it seeks to explain change. A crucial part of their argument takes up distinctions between methods identified by Theda Skocpol and Margaret Somers, in a famous 1980 article in the journal with the extremely relevant title Comparative Studies in History and Society. ${ }^{8}$ These methods, which the authors term "logics-of-use," are: 1) parallel demonstration of theory; 2) contrast of contexts; and 3) macrocausal analysis. ${ }^{9}$ Both 1 ) and 3 ) have a focus on causes and explanations (see below), while 2), to which the majority of articles in the present volume belong, is concerned more with exploring illuminating similarities and differences between pairs or groups of societies, generally without formulating laws or causal connections. As Skocpol and Somers note, their three types are idealized, and many works use more than one of the approaches. Nonetheless, type 2) is markedly different from the other two. In Egyptology, the most detailed and informed treatment known to me that takes the contrast of contexts approach, while also building toward a limited synthesis, is Anthony Barbieri-Low's forthcoming Ancient Egypt and Early China: State, Society, and Culture.

Parallel demonstration and macro-causal analysis seek to "explain," but in different ways, the former by proposing or developing a theory that is tested on different cases, the latter more broadly—and in principle perhaps more empirically—by treating a number of examples and inferring patterns from

7 Smith, Urban Life in the Distant Past (see his article in this volume).

8 "The Uses of Comparative History in Macrosocial Inquiry."

9 This is the order in which Skocpol and Somers discuss their types, and it is adopted by Hoyer and Manning. Skocpol and Somers's initial definition is in the order 3), 1), 2). Both pairs of authors are most interested in 3$)$. 
them. In focusing on explanation, the macro-causal approach in particular moves a little way toward the more statistically based arguments that are typical of economic history. In this respect it can be related to "Cliometrics,"10 a term evoking the Muse of History that was first used in 1960 for statistically informed history, became renowned notably for studies of the economics of slavery in the American South, and remains popular. Cliometrics uses voluminous data, together with statistical treatment of it, on a larger scale than earlier historians had done. While for ancient history Cliometrics is probably viable for an exceptionally well documented society, such as some periods of Mesopotamian history or Roman Egypt, for much of Egyptology comparable uses of statistics may continue to be typical of ceramicists and archaeological scientists but hardly of historians.

For many Egyptologists, approaches that provide explanations of change may feel uncomfortable because the record is fragmentary and proof is elusive. Such a reservation could, however, apply to almost any historical period and is probably unwarranted: we will never know everything about the past, and if we did, we would not be able to handle it. Attempting to explain change may not find as much favor as building interpretive understandings of the pastwith all the methodological qualifications already implied—but both are entirely legitimate aims. I now consider a little further the potential of largescale statistically-based comparison.

Rather as Skocpol and Somers build their argument toward their preferred macro-causal approach, Hoyer and Manning build theirs toward "Cliodynamics," a term they introduce near the end of their article. ${ }^{11}$ This term, which Peter Turchin devised in 2003, is intended to encapsulate the focus on change that is not obvious from the etymology of Cliometrics, although that too often addresses change. Turchin and Harvey Whitehouse collaborate to lead successive projects that collect data about societies across the world in order to explore regularities and test hypotheses about broad developments through comparative methods. In 2011 they founded the Seshat Databank (http:// seshatdatabank.info/) to assemble data, make it available to anyone interested, and provide a freely accessible platform for comparative research and for statistical testing of historical approaches across a very large selection of societies

10 Cliometrics is an enormous movement, for which Wikipedia provides a good basic reference: https://en.wikipedia.org/wiki/Cliometrics (checked 14 December 2020).

11 For Cliodynamics, which is also the title of a journal, Wikipedia again offers a convenient summary: https://en.wikipedia.org/wiki/Cliodynamics (checked 14 December 2020; not very up to date); journal: https://escholarship.org/uc/irows_cliodynamics (checked 14 December 2020). 
and societal types. The name Seshat was chosen as a suitable ancient goddess of learning from a non-European culture. ${ }^{12}$

The data that the Seshat project collects reach back to the late Neolithic and forward to premodern times. The questions that it addresses are to do with social change in the broadest sense. Issues can be quite specific, but all are addressed globally, through comparison of numerous "polities" (the term that Seshat uses for a unit of analysis). An example is testing the degree of correlation of the emergence of polities of imperial scale with agricultural potential, or alternatively with a long period of agricultural development before the appearance of empire. The latter is the preferred option. ${ }^{13}$ This result raises a question for Egypt, which does not fit very tidily into the pattern, as well as being a cross-cultural outlier in its character as a largely territorial state with a relatively high degree of stability. Another case is the incidence and meaning of human sacrifice, a medium-term project that is not yet published. Publication takes the form of articles and books that are developed out of curated and highly nuanced online datasets, together with presentation and bibliographical support for detailed interpretive choices, that are available on the website. ${ }^{14}$

Hitherto, the largest publication from the Seshat project is a book, Daniel Hoyer and Jenny Reddish (eds.), Seshat History of the Axial Age (2019), which reviews the famous hypothesis of Karl Jaspers in relation to societies in much of the world. ${ }^{15}$ By coincidence, that book-by a group which includes a chapter on Egypt co-authored by an Egyptologist, Joseph Manning - was published within a year of Jan Assmann's Achsenzeit: Eine Archäologie der Moderne (2018), a work by an Egyptologist that mentions Egypt throughout its dozen essays on authors who developed a less Eurocentric concept of worldwide change from the eighteenth to the early twenty-first century; Assmann thus treats a larger span of modern scholarship than that covered in the Seshat History. Hoyer, Reddish, et al., and Assmann independently agree that the Axial Age proposed by Karl Jaspers is a modern fiction, but in their concluding chapter the Seshat authors add a vital, ironically phrased nuance: "So, was there an Axial Age? We suggest the answer is 'sort of,' but it was not so much an age as a stage in the evolution of social complexity... . ${ }^{16}$ Assmann's book is a contribution to

\footnotetext{
12 Peter Turchin, personal communication (13 December 2020).

13 Currie, et al.,"Duration of Agriculture and Distance from the Steppe."

14 The datasets and statistical procedures used in each article are also placed online.

15 For a closely related article, see Mullins, et al., "A Systematic Assessment of 'Axial Age' Proposals."

16 "Conclusion: Was There Ever an Axial Age?" 406; for full authors of the chapter, see Bibliography below.
} 
the history of ideas, presenting the background and development of a concept in western, primarily European, thought. By contrast, the Seshat History focuses, after an introduction on the history of the concept of axiality, on evidence from ancient and less ancient societies, offering an altogether broader evidence base than predecessors. The two books are complementary, but the Seshat History belongs much more to the field of global history than Assmann's, which however has a different aim.

As Ian Morris notes in his Foreword to the Seshat History, ${ }^{17}$ Jaspers's Axial Age concept was explicitly teleological: history had a goal. A principal aim of the Seshat project, which has produced the publications just cited, is to illuminate important social changes that are commonly treated as phases of social evolution, and in that more limited sense it too is teleological, but without the same emphasis on western culture. Another aim is to test existing theories against a greatly enhanced amount and range of data. Morris also states, in my view correctly, that "Evolution is directionless." Insofar as research on the past is informed by the present and practitioners aspire to contribute positively to today's society and its thought, this absence of direction cannot be connected in any simple way with Juan Carlos Moreno García's concern in this journal volume with the "crisis of the humanities." But to remove the sense that history has a goal aids in the decentering that Miniaci and other contributors urge. Goal-directed visions of history have legitimized countless atrocities and show every sign of continuing to do so. Anything that may help to undercut them is welcome.

By placing a sketch of a comparative project that uses statistical methods deriving ultimately from the natural sciences at the end of this miniscule survey, I do not seek to privilege that approach over others. Application of quantitative measures for phenomena that need to be qualitatively assessed in a process of collection and analysis is difficult and may never be universally accepted, but it opens out new possibilities in explanation, and potentially also in detailed interpretation. As Hoyer and Manning note, methods like those of Cliodynamics and the Seshat project depend on specialized knowledge of the regions that they cover, while asking questions that are often of a different type, or on a different level of generality, from those addressed within any single region, of which ancient Egypt is an example. Comparison sets a phenomenon such as human sacrifice against that global background, and it is

17 Morris, "Foreword: For What It's Worth," 2; citation from p. 12. 
particularly valuable when scholars attempt to understand practices that are very alien to most modern human experience. It does not constrain interpretation of a practice's meaning in any specific context. Nor does Cliodynamics supersede other approaches to interpretation on a global scale. Thus, Chris Gosden's The History of Magic: From Alchemy to Witchcraft, from the Ice Age to the Present (2020), which devotes one chapter to Mesopotamia with Egypt, is very much to be welcomed for presenting a new angle on thinking about its topic and applying it to an amazingly broad timespan.

Ancient Egypt can contribute to many styles of history and historiesperhaps most distinctively to the global history which is becoming ever more important-as an instance that offers comparison and contrast for many other cases. At the same time, thinking about other societies and their institutions can enrich greatly the comprehension of Egyptian history, both broadly and at many levels of detail.

\section{Bibliography}

Assmann, J. Achsenzeit: Eine Archäologie der Moderne. Munich: C.H. Beck, 2018.

Bagley, R. "Art”. In A World with States, Empires, and Networks, C. Benjamin, ed., 179-234. Cambridge World History 4. Cambridge: Cambridge University Press, 2017.

Barbieri-Low, A. Ancient Egypt and Early China: State, Society, and Culture. Seattle: University of Washington Press, forthcoming.

Benjamin, C., ed. A World with States, Empires, and Networks, 1200 BCE-90o CE. Cambridge World History 4. Cambridge: Cambridge University Press, 2015,

Berger, P.L. and T. Luckmann. The Social Construction of Reality: A Treatise in the Sociology of Knowledge. Garden City, NY: Doubleday, 1966.

Currie, T.E., P. Turchin, E. Turner, and S. Gavrilets. "Duration of Agriculture and Distance from the Steppe Predict the Evolution of Large-scale Human Societies in Afro-Eurasia." Humanities and Social Sciences Communications 7 (2020): Article no. 34. doi: 10.1057/s41599-020-0516-2.

Ginzburg, C. The Cheese and the Worms: The Cosmos of a Sixteenth-Century Miller. Transl. J.A. Tedeschi and A. Tedeschi. London: Routledge/Kegan Paul, 1980 [1976].

Gosden, C. The History of Magic: From Alchemy to Witchcraft, from the Ice Age to the Present. London: Viking/Penguin, $202 \mathrm{O}$.

Hoyer, D. and J.G. Manning. "Empirical Regularities across Time, Space, and Culture: A Critical Review of Comparative Methods in Ancient Historical Research." Historia: Zeitschrift für Alte Geschichte 67, no. 2 (2018): 16o-19o.

Hoyer, D. and J. Reddish, eds. Seshat History of the Axial Age. Seshat Histories 1. Chaplin, CT: Beresta, 2019. 
Le Roy Ladurie, E. Montaillou, village occitan de 1294 à 1324. Paris: Gallimard, 1975. English: Montaillou: Cathars and Catholics in a French Village, 1294-1324. Transl. B. Bray. London: Scholar Press 1978.

Morris, I. "Foreword: For What It's Worth: Evidence and Models in the History of the Axial Age." In The Seshat History of the Axial Age, D. Hoyer and J. Reddish, eds., 1-12. Chapman, CT: Beresta, 2019.

Mullins, D. A., D. Hoyer, C. Collins, T. Currie, K. Feeney, P. François, P.E. Savage, H. Whitehouse, and P. Turchin. "A Systematic Assessment of 'Axial Age' Proposals Using Global Comparative Historical Evidence." American Sociological Review 83.3 (2018): 596-626. DOI: $10.1177 / 0003122418772567$.

Parsons, P.J. The City of the Sharp-Nosed Fish: Greek Lives in Roman Egypt. London: Weidenfeld \& Nicolson, 2007.

Skocpol, T. and M. Somers. "The Uses of Comparative History in Macrosocial Inquiry." Comparative Studies in Society and History 22.2 (1980): 174-197. doi: 10.1017/ Soo10417500009282.

Toynbee, A. A Study of History. 12 vols. London: Oxford University Press, 1934-1961.

Whitehouse, H., P. François, E. Cioni, J. Levine, D. Hoyer, J. Reddish, and P. Turchin. "Conclusion: Was There Ever an Axial Age?" In The Seshat History of the Axial Age, D. Hoyer and J. Reddish, eds., 395-407. Chapman, CT: Beresta, 2019.

Yoffee, N. "The Evolution of Fragility: The Resistible Rise and Irresistible Fall of Early States." In State Formation and State Decline in the Near and Middle East, R. Kessler, W. Sommerfeld, and L. Tramontini, eds., 5-13. Wiesbaden: Harrassowitz, 2016.

Yoffee, N., ed. Early Cities in Comparative Perspective, 4000 BCE-1200 CE. Cambridge World History 3. Cambridge: Cambridge University Press, 2015. 